\title{
EL SUJETO DE LA AVENTURA
}

\section{Subject of the adventure}

\author{
Pablo Black* \\ Universidad Nacional del Nordeste \\ pabloagustinblack@gmail.com
}

\section{1.}

Se abre el baúl de un auto, se arroja dentro un cuerpo sin vida o con apenas un hilo de vida, y se cierra el baúl. El auto se dirige a las afueras de la ciudad, a un sitio oscuro, poco frecuentado, un lugar donde sea difícil, cuando no imposible (todo depende de la pericia del criminal), hallar el cadáver. Tal es la escena prototípica del policial, del policial negro al menos, su cliché, la escena que está de fondo aun cuando no aparezca en la historia. En la literatura policial el cuerpo debe ocultarse, es algo de lo que hay que deshacerse, que perturba, que molesta. Exactamente lo contrario sucede en la narrativa de aventura, allí los cuerpos cuelgan ostensiblemente del arco de entrada al pueblo, o bien en la plaza principal, pendiente de un árbol o de un patíbulo, cuerpos de piratas, de asesinos, de señores del régimen anterior, cuerpos a la vista como elementos del paisaje, biodegradándose en medio del poblado, como si quitarlos fuera a alterar el equilibrio del ecosistema. Cuerpos o partes de cuerpos, cabezas en la pica, cabelleras, collares de orejas, ristra de dientes...

La aventura exhibe el cuerpo, lo expone. Y si no lo exhibe directamente, hace con ellos una gran pira, de manera que la densa columna de humo y el olor a carne chamuscada sean perceptibles a la distancia.

Es cierto, son situaciones extremas, ultraviolentas, en las que la exhibición del cuerpo, tan importante en la aventura, parece más bien la exhibición del flagelo del cuerpo, del flagelo como marca del poder, tal como lo estudiara Foucault en el capítulo "Suplicios", de Vigilar y castigar (1984), y como hoy día estilan hacer los grupos de narcos, quienes llevaron la crueldad sobre los cuerpos al grado de una sofisticada retórica. Y ahí está la tesis de Rita Segato en La escritura en el cuerpo de las mujeres asesinada en Ciudad Juárez (2013), donde el cuerpo de la mujer no solo es objeto en si de la violencia machista, sino también un medio del que se sirven determinados grupos de varones violentos y asesinos para enviar mensajes a otros grupos de varones violentos y asesinos con los que rivalizan.

Y eso, por supuesto, no tiene nada que ver con la aventura. Aquello es el reino de la muerte mientras que la aventura es la búsqueda incesante de las arterias de la vida, aunque en el esfuerzo, 
inevitablemente, se tope aquí y allá con la muerte. El cuerpo, y sobre todo la exhibición del cuerpo, es solo el punto en que ambas vertientes o programas coinciden, pero su oposición es de pe a pa, sobre todo en lo que tienen de más esencial: si la muerte es la clausura de la experiencia; la aventura por el contrario reside en zafar de toda captura, de todo arresto, de toda detención o enlentecimiento de la experiencia, en zafar de la muerte, en definitiva, que vendría a ser la detención por excelencia.

El cuerpo del sujeto de la aventura es la superficie de inscripción de la experiencia.

Todos los cuerpos en general, pero de forma explícita el de este sujeto, son antes que nada superficies de inscripción de acontecimientos. En la aventura el cuerpo se marca, pero sobre todo está marcado:

[Cuerpos] tatuados, marcados, llenos de costurones, las grandes cicatrices inauguradas Dios sabe dónde y por qué bárbaros cirujanos como rastros de gigantescos ciempiés en los torsos y los abdómenes, algunos deformes, sin uno o varios dedos, algún ojo, frentes y brazos estampado con letras y números como artículos para inventariar. (McCarthy, 2010, p. 205)

Las marcas del cuerpo trazan el recorrido de las experiencias del sujeto. De ahí el valor que en la aventura suele tener la descripción del personaje, la importancia crucial del rasgo visible. Pero aquí las descripciones no buscan tanto establecer una coherencia, una consistencia del personaje, como insinuar un cúmulo de vitalidad, llevarnos a dimensionar una potencia, lo que fueron capaces de hacer y hasta dónde estarían dispuestos a llegar... Describen procesos más que estados.

Un ejemplo, la descripción de Tía Encarna en Las malas, de Camila Sosa Villada:

La Tía Encarna tenía ciento setenta y ocho años. La Tía encarna tenía cortaduras de todo tipo, hechas por ella misma en la cárcel (porque siempre es mejor estar en enfermaría que en el corazón de la violencia) y también fruto de peleas callejera, clientes miserables y ataques sorpresivos. Incluso tenía una cicatriz en la mejilla izquierda que le daba un aire ruin y misteriosos. Sus tetas y sus caderas cargaban unos moretones eternos, a causa de las palizas recibidas cuando había estado detenida (...). No, me retracto: esos moretones eran por el aceite de avión con el que había moldeado su cuerpo, ese cuerpo de mamma italiana que le daba de comer, pagaba la luz, el gas, el agua para regar aquel patio hermosamente dominado por la vegetación, aquel patio que era la continuación del Parque, tal como el cuerpo de ella era la continuación de la guerra. (...)

Se había inyectado aceite de avión en las tetas, en las nalgas, en las caderas y en los pómulos. Decía que, además de ser económico, resistía mejor las embestidas. Por las zonas inyectadas se le había llenado de unos moretones desagradables y el líquido se había desplazado en cualquier dirección, dejándola llena de bultos y de pozos como la superficie lunar. (2019, p. 28)

Cada marca en el cuerpo de Tía Encarna es la inscripción de un hecho, de un evento, y al mismo tiempo la posibilidad de su narración. Y es entonces que damos con el verdadero espesor de la experiencia en la aventura. Sin duda la experiencia, su deriva incesante, el continuum de acontecimientos, es el tema de la aventura. Pero aquí, experiencia tiene una conformación específica: no remite solo a hechos sucedidos, sino también a su narración. En la aventura, la experiencia es el evento y su narración, 
y existe entre ambos componentes una presuposición ontológica: no hay evento sin narración, toda narración es del evento. Dice Giorgio Agamben: "la aventura no se sitúa ni únicamente en el texto ni únicamente en la serie de eventos, sino en su coincidencia, en su conjunción” (2018, p. 29).

John Berger retoma una idea de Susan Sontag, según la cual la fotografía sería un rastro directo de lo real, tal como una máscara mortuoria. La fotografía no es una representación del hecho, sino su rastro literal. Aprendemos a leer una fotografía como lo hacemos con una huella, la fotografía habla el lenguaje de los acontecimientos.

Dice Berger que el antecedente de la fotografía no es, como solemos suponer, el grabado, el dibujo o la pintura. El antecedente directo de la fotografía es la memoria; la fotografía es la memoria continuada por otros medios. Y dice otra cosa maravillosa Berger. Dice que, al ser memoria, rastro, huella, la fotografía es por naturaleza honesta, o valiente si se quiere. Su espíritu se define por la aceptación, por la aceptación del mundo tal cual es. "En un dibujo, una manzana se hace redonda y esférica; en una fotografía, la redondez, la luz y la sombra de la manzana se aceptan” (Berger, 2015, p. 74). Y en diálogo con el fotógrafo brasilero Sebastián Salgado (él mismo, Salgado y su obra, grandiosos exponentes de la aventura), Berger dice: "De alguna manera extraña, en todas tus fotos se percibe en tu visión la palabra 'sî', no porque apruebes lo que estás viendo, sino porque dices: 'sí, existe”' (2015, p. 200).

En la aventura los cuerpos son como fotografías, superficies de huellas, cuerpo-buella, cuerpotestigo. Por eso se exhiben. A diferencia del policial, incluso del policial más cruento y descarnado, donde el cuerpo suele leerse como una metáfora, una abstracción, en la aventura el cuerpo es una superficie literal, huella de inscripción de eventos que pueden o podrían ser narrados, precisamente gracias a esa inscripción.

2.

"La trama", relato de Borges publicado en El hacedor:

Para que su horror sea perfecto, César, acosado al pie de la estatua por los impacientes puñales de sus amigos, descubre entre las caras y los aceros la de Marco Bruto, su protegido, acaso su hijo, y ya no se defiende y exclama: “Tú también, hijo mío!” Shakespeare y Quevedo recogen el patético grito.

Al destino le agradan las repeticiones, las variantes, las simetrías; diecinueve siglos después, en el sur de la provincia de Buenos Aires, un gaucho es agredido por otros gauchos y, al caer, reconoce a un ahijado suyo y le dice con mansa reconvención y lenta sorpresa (estas palabras hay que oírlas, no leerlas): “PPero, che!” Lo matan y no sabe que muere para que se repita una escena. (2001, p. 32-33)

Cada vez que leo un cuento de Borges, además de agradecer a dios, me pregunto cómo lo habría leído Ricardo Piglia, que fue uno de sus lectores más deslumbrantes. Y qué duda cabe, Piglia nos indicaría concentrarnos en la segunda historia, en la historia que se narra (que no se narra) a partir de las formas diversas en que César y el Gaucho expresan su sorpresa, el “iTú también, hijo mío!” y el “¡Pero, che!”. Deténganse en la segunda historia, diría Piglia, pero cuídense bien de no quedar captados por el primer sentido que esta, la segunda historia, sugiere, es decir, el sentido que 
nos lleva a colegir que ambas expresiones serían meras variaciones de un mismo acontecimiento, de un acontecimiento idéntico a sí mismo que retornaría con dos apariencias diferentes. No, vayan al otro sentido, insistiría, al sentido que abre el problema, al que sugiere que la diversidad entre las expresiones de César y del Gaucho remite en realidad no a una identidad sino a otra diversidad, más profunda, a saber: la disparidad del acontecimiento consigo mismo. En otras palabras, lo diverso no serían solo las dos apariencias del acontecimiento, también, sobre todo, el acontecimiento mismo; el acontecimiento vuelve, es cierto, se repite, pero nunca, jamás, es el mismo acontecimiento el que regresa.

Y entonces caemos en la cuenta de que no solo hemos invocado a Piglia, de repente, también metimos a Deleuze (su teoría del acontecimiento) en nuestra lectura.

Para Deleuze el acontecimiento se realiza dos veces, en dos registros al mismo tiempo. Una vez de forma personal (la traición que sufre el hombre César, la que sufre la persona del Gaucho) y otra vez de forma impersonal (el acontecimiento traición -traicionar, en infinitivo, diría Deleuze- que se actualiza en César, que se actualiza en el Gaucho). O dicho en otros términos: por un lado está el acontecimiento de la traición que sufren los respectivos cuerpos de César y del Gaucho; y por otro el acontecimiento incorporal traicionar que se libera, que se emite, gracias a su actualización en los cuerpos de César y del Gaucho. Una realización personal-corporal del acontecimiento y otra impersonal (o neutra)-incorporal. Siempre el segundo acontecimiento depende de su actualización en un cuerpo determinado, no hay otro modo en que pueda darse, pero su alcance es infinito, infinitamente más acá y más allá del presente del cuerpo en que se da.

Entonces, las dos realizaciones del acontecimiento: el pequeño, la historia de traición a César, la historia de la traición al Gaucho; y el grande, que se actualiza en el pequeño, pero alcanza a la Gran Historia de las traiciones habidas y por haber a lo largo y ancho del universo.

Hablando con propiedad, para Deleuze, el acontecimiento puro, el mero, es el incorporal. E1 otro, el corporal, vendría a ser más bien el hecho o el suceso, la oportunidad para que el acontecimiento (incorporal) se actualice y se despliegue a través de todo el tiempo. "El acontecimiento no es lo que sucede; está en lo que sucede”, decía Deleuze (2005, p. 157).

Más que sucederme a mí, el acontecimiento se actualiza en mí. Soy actor del acontecimiento, lo encarno. Pero ese lugar subalterno respecto de lo que me sucede, no es algo que asumamos con facilidad y mucho menos de buen grado. Yo y mis acontecimientos es preferible a los Acontecimientos y yo. De ahí que lo habitual sea quedarse en la realización personal (mi suerte y mis desgracias, mis sucesos particulares), que sobrepasar el límite narcisista y dirigirse al registro del acontecimiento puro, hacia su "esplendor neutro", donde el hecho personal, mi pequeña tragedia o ventura, se deshace batida por una gran risa impersonal.

Bien. Se dirá que el sujeto de la aventura es deleuziano... Y sí, qué duda cabe... Existen flagrantes afinidades entre aquel y esta filosofía, aunque lo más probable es que Deleuze fuera aventurero.

El sujeto de la aventura es el enamorado del acontecimiento, y su cuerpo, dijimos, la superficie de inscripción de la experiencia. La deriva incesante de los acontecimientos es el principio rector de 
nuestro sujeto, la deriva incluso más allá de los límites, de las fuerzas del sujeto. Segui vos, se dice en la aventura cuando no se puede más. O como exponía un viejo marinero en La taza de oro de Steinbeck:

¿quieres ser marinero? Eso no es tan difícil. Primero has de aprender a soportar cosas de las que los hombres de tierra ni siquiera han oído hablar. Eso es lo primero. Es muy duro, pero si empiezas no lo dejas nunca, mírame a mí, hace doce años que intento llevar mi viejo casco a tierra y amarrarlo junto al fuego. Quería pensar durante un tiempo y morir. Pero es inútil. Siempre acabo corriendo a enrolarme en algún barco, el que sea. (2006, p. 52)

Pero la cosa no es tan sencilla, hay obstáculos... Se da una condición de tinte dialéctico en el sujeto de la aventura, una condición bien sabida por este sujeto, y que radica en que cada nuevo evento que sale al cruce del sujeto conlleva un riesgo de enlentecimiento, cuando no de detención lisa y llana, de la deriva de los acontecimientos: puede resultar herido, o traumatizado, o incluso muerto. Hay un cuento de Martín Rejtman, "Tres puntos rojos”, que pone sobre la mesa esta suerte de dialéctica del sujeto de la aventura, el deseo del acontecimiento y los riesgos que ese lance conlleva. (Los cuentos de Rejtman no se parecen a lo que suelen ser las narraciones de aventura, carecen de la mímesis aristotélica que tanto facilitaría las cosas. No obstante, son perfectos ejemplares de la aventura, en la medida en que presentan las problemáticas de esta como pocos. Sus personajes urbanos, por lo general jóvenes en apariencia abúlicos e inconsistentes, son sin embargo criaturas de la aventura de pura cepa, solo que insertadas en contextos extraños a los escenarios típicos del género.) El narrador de "Tres puntos rojos" es un sujeto preocupado por los efectos de las marcas, los riesgos de la huella. Las marcas luego de una afeitada (los tres puntos rojos), son el disparador de la pregunta por cuáles son las muescas definitivas, aquellas que lo detienen a uno. Una separación, el sobrepeso... Todos posibles modos de quedar capturado. Dice:

Cada mañana me levanto y me miro al espejo. Mi imagen no parece variar demasiado. A veces los pliegues de las sábanas me quedan marcados en el cuerpo. Son marcas que desaparecen al poco tiempo, como las de las esterillas de algunas sillas en la mano. La piel se pone roja por la presión del contacto y al notarlo, por un momento creemos que va a quedar así para siempre. (Rejtman, 2007, p. 118)

Son algunos de los riesgos que traen los eventos, pero ni siquiera los más terribles ni habituales. Hay uno que sí es grave, el peor de todos quizás, el desliz imperdonable que no se puede permitir el sujeto de la aventura. A saber: tomarse los hechos a título personal, quedar atrapado en la realización corporal del evento, en su dimensión personal, el riesgo de ser captado, absorbido, por el pequeño acontecimiento. Pues entonces el sujeto encallará y ya no podrá salir de lo que le ha sucedido: se ahogará en su lamento, en su queja, o en aquella oportunidad en que fue feliz, lo mismo da, pero ya no podrá pasar a otra cosa.

Por eso, lo fundamental para el sujeto de la aventura no es tanta la variedad ni el número de los acontecimientos que atraviesa, sino su disposición para recibirlos, el modo de lidiar con ellos.

Y aquí es cuando volvemos al cuento de Borges. Aquellos modos diversos de expresar la traición son en verdad maneras extremas, en las antípodas, de recibir el acontecimiento: la patética, trágica y personal de César, “¡Tú también, hijo mío!”, frente al impersonal, al desapasionado “¡Pero, che!” del 
Gaucho, expresión de corte aventurero que se distancia de la emoción en el preciso instante en que el hecho sucede, y que por esto mismo, por esta distancia emocional que logra, hace de su respuesta al hecho algo tierno, humorístico, emocionante. La diferencia entre las expresiones es la diferencia exacta entre evento y Acontecimiento, deleuzianamente hablando. $\mathrm{O}$ en otros términos: el Acontecimiento sucede dos veces, una vez como tragedia y otra como aventura.

Desapasionar el acontecimiento, quitarle su certeza emotiva, neutralizar el sentimiento esperable, la emoción codificada, aquella que pegotea a la persona con el evento, es, poco más, poco menos, el movimiento esencial del sujeto de la aventura. No es que sea insensible, ni que nada le importe, sino que lo importante nunca es personal. En cierta forma, el proyecto del sujeto de la aventura es de otro planeta, una suerte de utopía, de sueño o delirio de la experiencia incesante. De ahí que a menudo sus avatares resulten inverosímiles, y hasta inhumanos, que la resistencia de que son capaces no pueda ser más que un producto de la imaginación. Y puede ser... quién sabe... A fin de cuentas, no será la primera ni la última vez que haya que recurrir a la evasión, al acontecimiento imaginario, para generar las condiciones en que puedan danzar los hechos más ciertos de este mundo.

\section{Referencias bibliográficas}

Agamben, G. (2018). La aventura. Ciudad Autónoma de Buenos Aires, Adriana Hidalgo (original publicado en 2015).

Berger, J. (2015). Para entender la fotografía. Barcelona, Gustavo Gili (original publicado en 2013).

Borges, J. L. (2001). “La trama”. En: El hacedor. Ciudad Autónoma de Buenos Aires, Planeta (original publicado en 1960).

Deleuze, G. (2005). Lógica del sentido. Ciudad Autónoma de Buenos Aires, Paidós (original publicado en 1969).

Foucault, M. (1984). Vigilar y castigar. México, Siglo Veintiuno.

McCarthy, C. (2010). Meridiano de sangre. Barcelona, Mondadori (original publicado en 1985).

Rejtman, M. (2007). “Tres puntos rojos”. En: Rapado. Ciudad Autónoma de Buenos Aires, Interzona (original publicado en 1992).

Segato, L. R. (2013). La escritura en el cuerpo de las mujeres asesinadas en Ciudad Juárez. Ciudad Autónoma de Buenos Aires, Tinta Limón.

Sosa Villada, C. (2019). Las malas. Ciudad Autónoma de Buenos Aires, Tusquets.

Steinbeck, J. (2006). La taza de oro. España, Edhasa (original publicado en 1929). 
* Pablo Black es Licenciado en Psicología (Universidad de la Cuenca del Plata). Es Profesor Adjunto del Seminario de Literatura y otros Discursos Sociales Contemporáneos II (Universidad Nacional del Nordeste). Fue Profesor en la Facultad de Psicología en la UCP y en la UCES (Universidad de Ciencias Empresariales y Sociales). Es escritor y dirigió junto a Mariano Quirós las colecciones de narrativa Viceversa (Editorial Recovecos, Córdoba) y Mulita (Editorial Contexto, Resistencia).

RECIBIDO: 29/06/2020

AcEPTAdo: 27/07/2020 